\title{
Semaphorin 5A Promotes Gastric Cancer Invasion/Metastasis via Urokinase-Type Plasminogen Activator/Phosphoinositide 3-Kinase/Protein Kinase B
}

\author{
Guoqing Pan $\cdot$ Zhu Zhu $\cdot$ Jian Huang $\cdot$ Chenggang Yang $\cdot$ \\ Ying Yang $\cdot$ Yingxia Wang $\cdot$ Xiaoyu Tuo $\cdot$ Guomiao Su $\cdot$ \\ Xiangling Zhang $\cdot$ Zhi Yang $\cdot$ Tao Liu
}

Received: 11 October 2012/Accepted: 27 March 2013/Published online: 10 May 2013

(C) The Author(s) 2013. This article is published with open access at Springerlink.com

\begin{abstract}
Background Semaphorin 5A, a member of the semaphorin family, was originally identified as an axonal guidance factor functioning during neuronal development. Previously, we showed that the expression of semaphorin 5A might contribute to the metastasis of gastric cancer. However, less information is currently available as to the involvement of uPA in the semaphorin 5A-induced metastasis and invasion of gastric cancer cells.

Aim The present study was designed to test whether semaphorin $5 \mathrm{~A}$ mediates the invasion and metastasis of gastric cancer via PI3K/Akt/uPA signaling.

Methods The semaphorin 5A-overexpressing cell was established from the gastric cancer cell line AGS. The effect of semaphorin 5A on the expression of uPA was evaluated by ELISA and Western blotting as well as RTPCR assays, respectively. Synthetic or natural inhibitors and dominant-negative mutants were used to determine the
\end{abstract}

Guoqing Pan, Zhu Zhu and Jian Huang contributed equally to this work.

G. Pan $\cdot$ Y. Yang $\cdot$ Y. Wang $\cdot$ X. Tuo $\cdot$ G. Su

Department of Pathology, The First Affiliated Hospital

of Kunming Medical University, Kunming, Yunnan,

People's Republic of China

\section{Z. Zhu $\cdot$ J. Huang $\cdot$ C. Yang}

Department of Tumor Surgery, The First Affiliated Hospital

of Kunming Medical University, Kunming, Yunnan,

People's Republic of China

\section{Zhang ( $\square)$}

Department of Blood Transfusion, The First Affiliated Hospital of Kunming Medical University, Xichang Road \#294, Kunming, Yunnan 650032, People's Republic of China

e-mail: guoqing_pan@163.com hierarchical relationship between semaphorin 5A, PI3K/ Akt and uPA in the invasion and metastasis of gastric cancer.

Results Overpression of semaphorin 5A enhanced the expression of $\mathrm{UPA}$, and synthetic or natural inhibitors of uPA abolished semaphorin 5A-induced cell migration and invasion. Semaphorin $5 \mathrm{~A}$ overexpression promoted the phosphorylation of Akt. Blocking effects of PI3K/Akt using pharmacologic inhibitors, dominant-negative mutants abolished the ability of semaphorin $5 \mathrm{~A}$ to induce uPA expression and cell invasion and migration.

Conclusion Semaphorin 5A could promote invasion and metastasis of gastric cancer through the PI3K/Akt/uPA signal transduction pathway. Semaphorin 5A and its regulated molecules could be the potential targets for cancer therapy.

Keywords Semaphorin 5A · Gastric cancer · Urokinasetype plasminogen activator (uPA) - Phosphoinositide 3-kinase (PI3K) · Protein kinase B (Akt)

\footnotetext{
Z. Yang $(\bowtie)$

Department of Dermatology, The First Affiliated Hospital of Kunming Medical University, Xichang Road \#294, Kunming, Yunnan 650032, People's Republic of China e-mail: vipyz@126.com

T. Liu $(\bowtie)$

Department of Pathology, The First Affiliated Hospital of Yunnan Traditional Chinese College, Guanghua Street \#120, Kunming, Yunnan 650021, People's Republic of China e-mail: chentb1234567@126.com
} 


\section{Introduction}

Gastric carcinoma is one of the most frequent causes of cancer-related deaths in the world, and current treatment options have made little impact on the overall survival rate $[1,2]$. Most gastric cancer patients have metastatic disease at the time of diagnosis with an extremely poor prognosis [3]. Therefore, further understanding the molecular mechanism(s) of gastric cancer may provide an insight into the development of novel diagnostics and targeted therapeutics.

The semaphorin represents a large family of genes that currently contain more than 30 members, characterized by a conserved sema domain of 500 amino acids. Based on sequence similarity and distinctive structural features, these genes have been grouped into eight subclasses (1-8) [4]. Semaphorin 5A belongs to class 5 of the semaphorin family, and is an integral membrane protein with seven characteristic thrombospondin specific repeats (TSP-1), which was originally identified as axonal guidance factor functioning during neuronal development [5, 6]. Our previous data have demonstrated that semaphorin $5 \mathrm{~A}$ was overexpressed in gastric cancer tissues, indicating a possible role for semaphorin $5 \mathrm{~A}$ in occurrence and development of gastric cancer $[7,8]$. In a recent study, we also found that semaphorin $5 \mathrm{~A}$ enhances the invasion and metastasis of human gastric cancer through activation of MMP9 [9]. However, further analysis of the semaphorin 5A-induced signaling pathway was expected to provide us with a better understanding of the activity of semaphorin $5 \mathrm{~A}$, and also on the mechanisms underlying the invasion and subsequent metastasis of gastric cancer cells.

A critical event in tumor invasion and metastasis is the ability of tumor cells to invade through the extracellular matrix (ECM), allowing tumor cells to move beyond the confines of the primary tumor environment [10]. At present, it has been established that tumor cell invasion through ECM and tissue barriers requires the combined effects of increased cell migration and regulated proteolytic degradation of matrix. Urokinase-type plasminogen activators (uPAs) are well identified to mediate the abnormal matrix remodeling occurring during human cancer progression. Such a system generates plasmin activity from plasminogen and provides the necessary conditions for tumor cells to invade the surrounding tissues, thus promoting metastasis development. In addition, more recent studies indicate that the PI3K/Akt pathway participates in the activation of many human tumors $[11,12]$. Therefore, in this study, we investigated the possible involvement of uPA in semaphorin 5A-induced signaling, and also analyzed their relationship to the PI3K-Akt pathway. Our data presented the first evidence that overexpression of semaphorin 5A was sufficient to induce increases in gastric cancer cell migration and invasion by inducing uPA expression via activation of the PI3K/Akt pathway.

\section{Materials and Methods}

\section{Cell Culture and Transfection}

The gastric cancer cell line AGS was maintained in DMEM (GIBCO, Carlsbad, CA, USA) containing $10 \%$ heat inactivated fetal bovine serum (FBS), $100 \mathrm{U} / \mathrm{ml}$ of penicillin and $100 \mu \mathrm{g} / \mathrm{ml}$ of streptomycin at $37{ }^{\circ} \mathrm{C}$ in a humidified atmosphere of $5 \% \mathrm{CO}_{2}$ and $95 \%$ air. Expression constructs were prepared using pcDNA3.1 vectors and transfected into cells using Lipofectamine 2000 (Invitrogen, Carlsbad, CA, USA). Transfected cells were selected by using $3 \mathrm{mg} / \mathrm{ml} \mathrm{G} 418$ sulfate. Heterogeneous populations of stably transfected cells were used in this study to avoid any possible clonal variations.

\section{RT-PCR Analysis}

Total RNA was extracted from specimens using Trizol reagent (Invitrogen). After RNA was quantified, cDNA was synthesized from $5 \mu \mathrm{g}$ of total RNA according to the manufacturer's guidelines in a total volume of $20 \mu \mathrm{l}$ (Fermentas Maryland, USA). Primers used for RT-PCR were as follows: uPA-f, 5'-CACGCTTGCTCACCACA-3', and uPA-r, 5'-CTTCAGGGCACATCCAC-3'; $\beta$-actin-f, $5^{\prime}$-CACGCACGATTTCCCGCTCGG- $3^{\prime}$, and $\beta$-actin-r, 5'-CAGGCTGTGCTATCCTGTAC-3'. The PCR was performed at $94{ }^{\circ} \mathrm{C}$ for $5 \mathrm{~min}$ followed by 30 cycles at $94{ }^{\circ} \mathrm{C}$ for $30 \mathrm{~s}, 57^{\circ} \mathrm{C}$ for $30 \mathrm{~s}$, and $72^{\circ} \mathrm{C}$ for $40 \mathrm{~s}$ with a PCR Thermal Cycler Dice (Takara, Otsu, Japan). $\beta$-actin was used as an internal control.

\section{Western Blotting Analysis}

The cells were homogenized in lysis buffer. Equal amounts of protein were subjected to $10 \%$ SDS-polyacrylamide gel electrophoresis, and transferred to polyvinylidene difluoride (PVDF) membrane. The membranes were blocked with $5 \%$ nonfat milk and incubated with primary antibody $(\mathrm{Ab})$. After three washes for $15 \mathrm{~min}$ in tris-buffered saline (TBS) supplemented with $0.1 \%$ Tween 20 (TBST), the membranes were incubated with horseradish peroxidase conjugated rabbit anti-mouse secondary Ab, followed by enhanced chemiluminescence (KPL, Gaithersburg, USA). Primary antibodies against semaphorin 5A, uPA, Akt and $\beta$-actin were applied at the optimized concentrations (Santa Cruz Biotechnology).

\section{ELISA Analysis}

The supernatant of the examined cells was centrifuged for $10 \mathrm{~min}$ at $2,000 \times \mathrm{g}$ then collected and stored in $-80{ }^{\circ} \mathrm{C}$ until use. In order to activate the samples, $100 \mu \mathrm{l}$ of each sample were incubated with $20 \mu \mathrm{l}$ of $1 \mathrm{~N} \mathrm{HCl}$ for $10 \mathrm{~min}$ at 
room temperature. The sample was then neutralized by adding $20 \mu \mathrm{l}$ of $1.2 \mathrm{~N} \mathrm{NaOH} / 0.5 \mathrm{~mol} / \mathrm{l}$ HEPES. Active uPA level was measured by ELISA kit (QuantikineTM, R\&D, Minneapolis, MN, USA) according to the instructions of the manufacturer.

\section{Cell Motility Assay}

Gastric cancer cell motility was assessed using a wound healing assay. The examined cells $\left(5 \times 10^{4} /\right.$ well $)$ were seeded in a six-well plate coated with fibronectin and cultured until confluent to get cell monolayers, which were then carefully wounded using sterile pipette tips, and any cellular debris was removed by washing with PBS. Photos were captured at 0,24 and $36 \mathrm{~h}$ after wounding.

\section{Cell Migration and Invasion Assay}

To determine the migration ability, the examined cells were plated on cell culture inserts uncoated with Metrigel in 24-well plates $(8-\mu \mathrm{m}$ pore size; Becton-Dickinson Labware) in serum-free medium, and $700 \mu$ of DMEM containing $10 \%$ bovine serum was added into the lower compartment. The invasion assay was similar to the migration procedure described above, except that the upper side of the membranes was coated with a uniform thickness of $50 \mu \mathrm{g}$ Matrigel for $1 \mathrm{~h}$ at room temperature before experiment. In some inhibitory experiments, inhibitors and $\mathrm{Ab}$ were also added to the upper chambers. The cells were allowed to invade for $24 \mathrm{~h}$ at $37^{\circ} \mathrm{C}$ in a $5 \% \mathrm{CO}_{2}$ humidified incubator. Next, the cells were removed from the upper surface of the filter with the cotton swab, and the cells that had invaded the bottom surface of the filter were fixed with methanol and stained with hematoxylin. The invasiveness was determined by counting the penetrating cells under a microscope at $200 \times$ magnification on ten random fields in each well.

\section{Tail Vein Metastatic Assay}

Female athymic Balb/c nude mice (Slac Laboratory Animal Co. Ltd., Shanghai, China) were used in the metastasis model and housed in individually ventilated cages of isolated ventilation. The use of animals in this study complies with the Guide for the Care and Use of Laboratory Animals (National Institutes of Health [NIH] publication no. 86-23, revised 1985) and the current Chinese law on the protection of animals. Cells were harvested from tissue culture flasks using trypsin and washed three times with PBS. Mice were injected with $1 \times 10^{6}$ cells in $0.1 \mathrm{ml}$ PBS through the tail vein. The mice were then monitored for overall health and total body weight. At the end of the experiment (the 23rd day), mice were sacrificed. The liver tissues were observed with the naked eye and the number of visible tumors in liver surface was counted. Liver tissues were made into serial sections before being HE dyed and observed under a light microscope. Each experimental group contained five mice.

\section{Statistical Analysis}

All experiments were performed at least three times, and the results were from representative experiments. The results were presented as mean $\pm \mathrm{SD}$. The data were analyzed by ANOVA. The statistical analysis was done using SPSS 11.0 software (SPSS) and $P<0.05$ was considered significantly.

\section{Results}

Overexpression of Semaphorin 5A Promotes Motility, Migration, Invasion, and In Vivo Metastasis Abilities of Gastric Cancer Cells

To further demonstrate the roles of semaphorin $5 \mathrm{~A}$ in invasiveness and metastasis of gastric cancer cells, AGS cells were infected with pcDNA3.1 to overexpress semaphorin 5A. After 9 days of infection, semaphorin 5A protein was detected to be expressed at a high level (Fig. 1a). Additionally, AGS cells infected with vector were used as a control group. The effect of semaphorin 5A on the motility capability of AGS cells was analyzed using a wound healing assay. As shown in Fig. 1b, c, when transfected with semaphorin $5 \mathrm{~A}$, cell flattening and spreading along the edges of the wound was enhanced compared with control. Similarly, the migration ability of the AGS cells was promoted when transfected with semaphorin 5A (Fig. 2a, b). A modified Transwell chamber assay was performed to determine the effect of semaphorin $5 \mathrm{~A}$ on the ability of AGS cells invading biological matrices in vitro. As shown in Fig. 2a, c, when transfected with the semaphorin 5A gene, the cells invading capabilities through the filter coated with Matrigel were increased by $200.28 \%(P<0.001)$ compared with the control. The tail vein metastatic assay in nude mice was further adopted to examine the in vivo metastatic ability of AGS cells when transfected with semaphorin 5A. Compared with control cells, i.v. inoculation of AGS cells transfected with semaphorin 5A led to significantly visible tumors in liver surface (Fig. 2d). Those results indicate that overexpression of semaphorin $5 \mathrm{~A}$ was sufficient to increase the motility, migration, invasion and metastasis of gastric cancer cells. 
Fig. 1 Effect of semaphorin 5A overexpression on the motility of gastric cancer cells. AGS cells were infected with semaphorin $5 \mathrm{~A}$ and vector, respectively. a The expression of semaphorin 5A was analysed by Western blotting and the $\beta$-actin band served as a protein control. b Semaphorin 5A promotes the wound healing ability of AGS cells.

c Statistical plot of motility of assay. $* P<0.01$ versus control

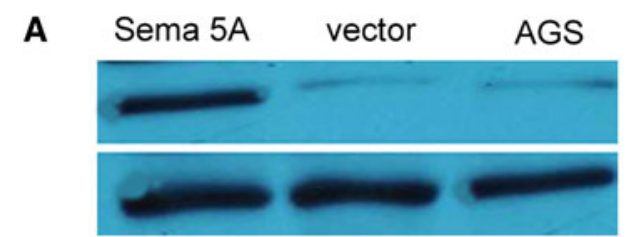

\section{Sema $5 A$}

\section{$\beta$-actin}

B AGS

vector

Sema 5A
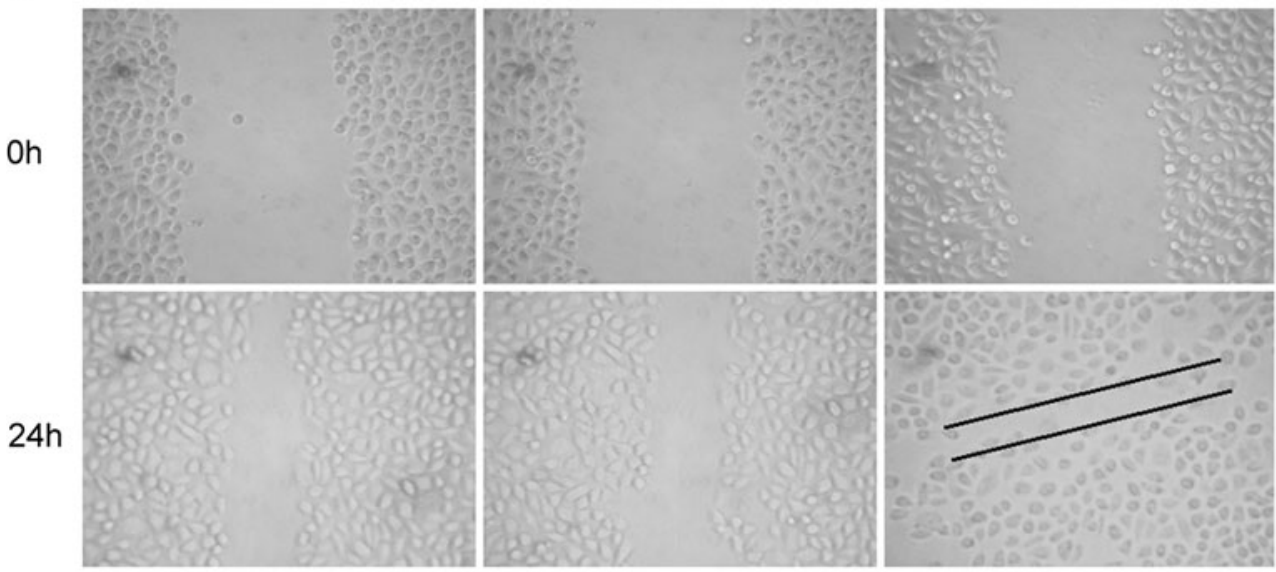

$36 \mathrm{~h}$
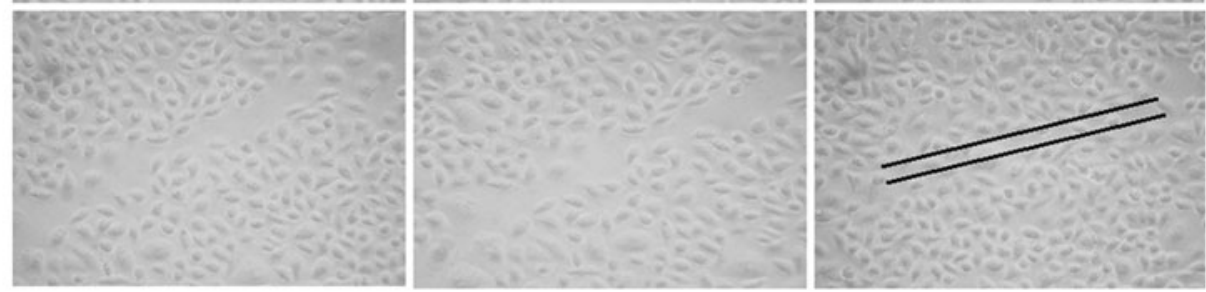

C

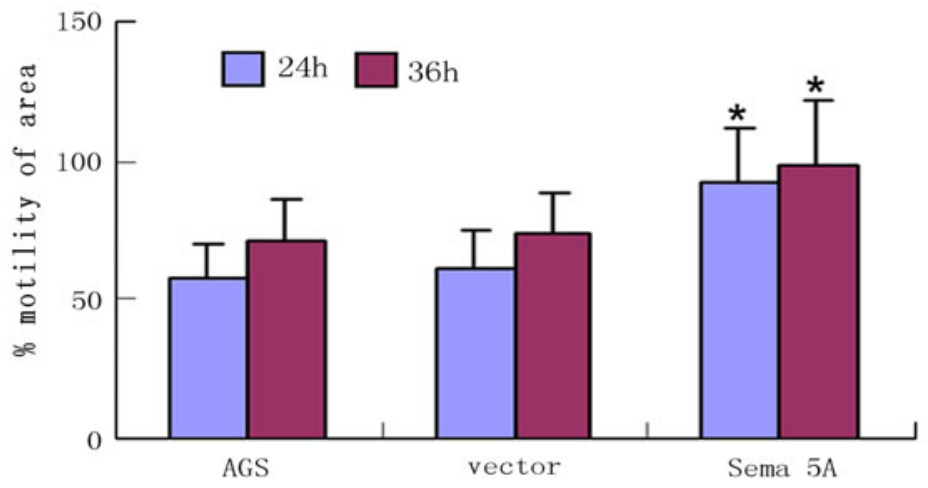

Semaphorin 5A Up-Regulates the Expression of uPA in Gastric Cancer Cells

We explored the expression of uPA to determine the cellular components involved in semaphorin 5A-induced invasion and metastasis. As shown in Fig. 3a, b, the overexpression of semaphorin 5A in AGS cells essentially led an increase in the expression of uPA protein and mRNA, as demonstrated by using Western blotting, ELISA and RT-PCR assays, respectively, indicating that semaphorin 5A up-regulates the expression of uPA in gastric cancer cell. As semaphorin 5A promoted cell motility, migration, and invasion in vitro, we propose that semaphoring 5A may indirectly up-regulate the expression of uPA.

uPA Mediates Semaphorin 5A-Induced Migration and Invasion

To determine the role of uPA in the invasiveness and migration of gastric cancer cell mediated by semaphorin $5 \mathrm{~A}$, the cells were preincubated with anti-uPA Ab and aprotinin, a specific inhibitor of plasmin activity, respectively, and then subjected to migration and invasion assays. The data shown in Fig. $3 \mathrm{c}, \mathrm{d}$ showed that the preincubation of uPA antibodies significantly abolished semaphorin 5A-induced increases in gastric cancer 
Fig. 2 Effects of semaphorin $5 \mathrm{~A}$ overexpression on the migration, invasion and metastasis of gastric cancer cells. a Semaphorin 5A promotes the migration and invasion of AGS cells.

b Statistical plot of migration of assay. c Statistical plot of invasion of assay. d Semaphorin $5 \mathrm{~A}$ promotes the metastasis of AGS cells in vivo. $* P<0.01$ versus control

\section{A

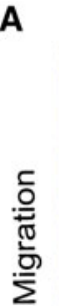
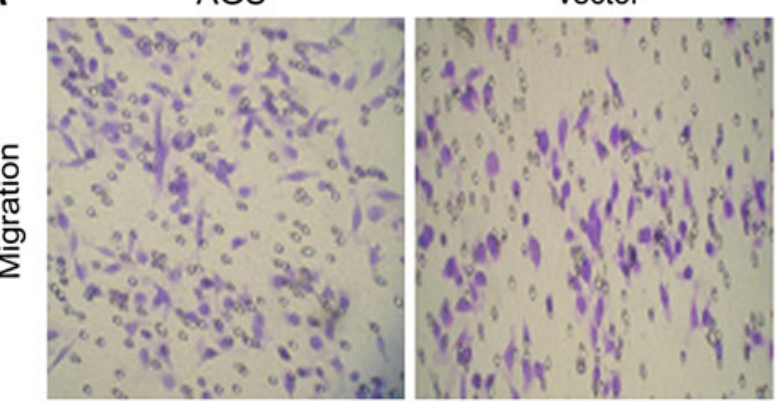

Sema $5 A$
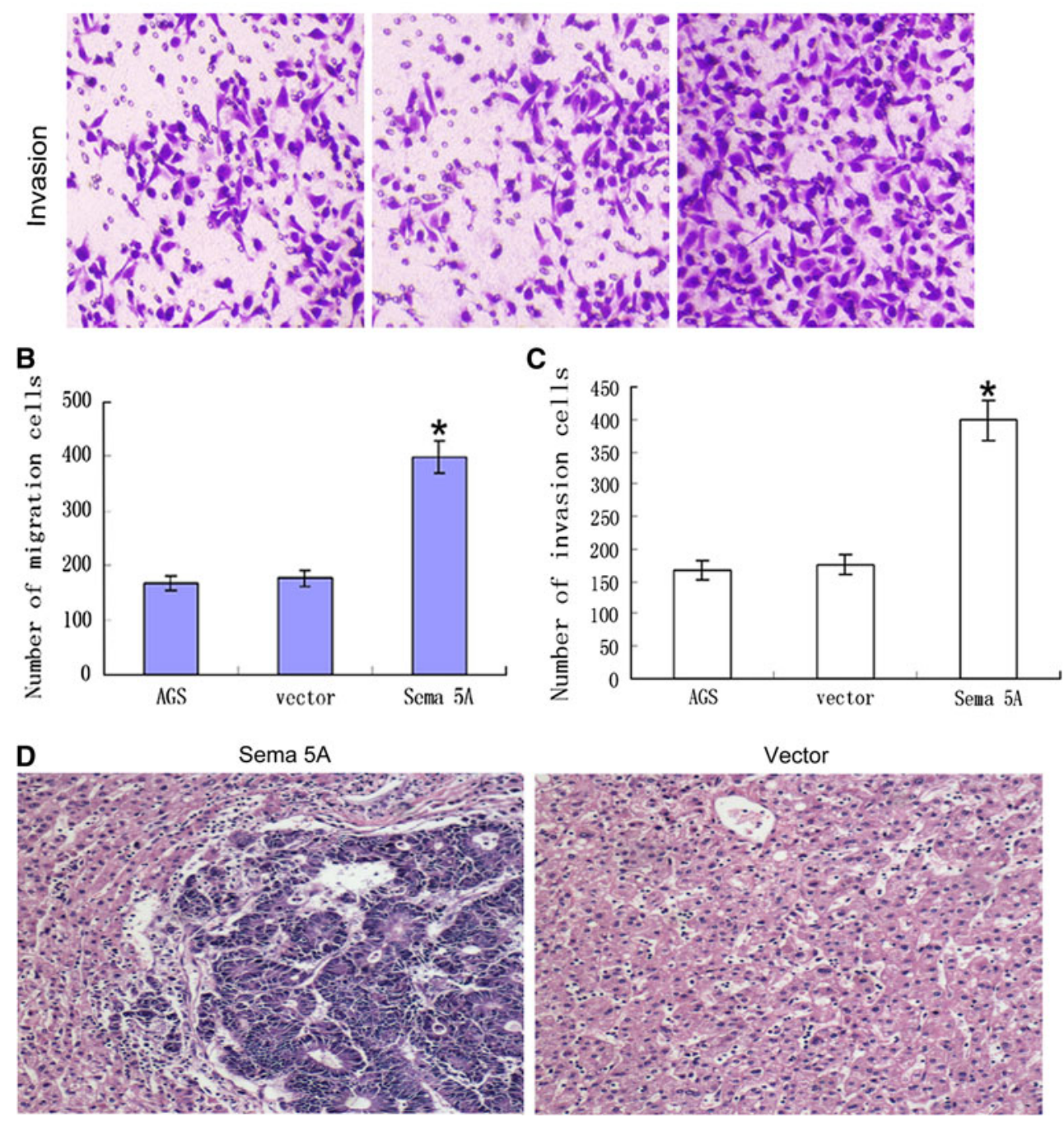

cell migration and invasion. Similar results were observed when the assay was conducted in the presence of aprotinin (Fig. 3c, d). These results indicate that uPA activity is required for semaphorin 5A-induced cell invasion and migration.

\section{PI3K/Akt Pathway Was Involved in Gastric Cancer Invasion}

To determine whether this pathway is required for semaphorin 5A-induced invasion and migration of gastric cancer cells, the cells were preincubated with LY294002 (LY), an inhibitor of PI3K and Akt-inhibitor (Akt-I), and then subjected to migration and invasion assays. Experimental results showed that the addition of any of these inhibitors could abolish semaphorin 5A-induced increases in gastric cancer cell migration and invasion (Fig. 4a, b). We examined the effect of semaphorin 5A on the phosphorylation of Akt, a major downstream target of PI3K, to further confirm this pathway involved.

Figure $4 \mathrm{c}$ showed that overexpressing semaphorin $5 \mathrm{~A}$ enhanced the phosphorylation of Akt, that is, activated Akt. 
Fig. 3 Semaphorin 5A promotes the migration and invasion of AGS cells by inducing uPA. a, b Semaphorin 5A up-regulates the expression of uPA, as demonstrated by Western blotting and Elisa as well as RT-PCR assays, respectively. c, d Anti-uPA antibody and aprotinin suppress semaphorin 5A-induced migration and invasion of AGS cells. $* P<0.01$ versus control; ${ }^{\#} P<0.05$ versus control
A
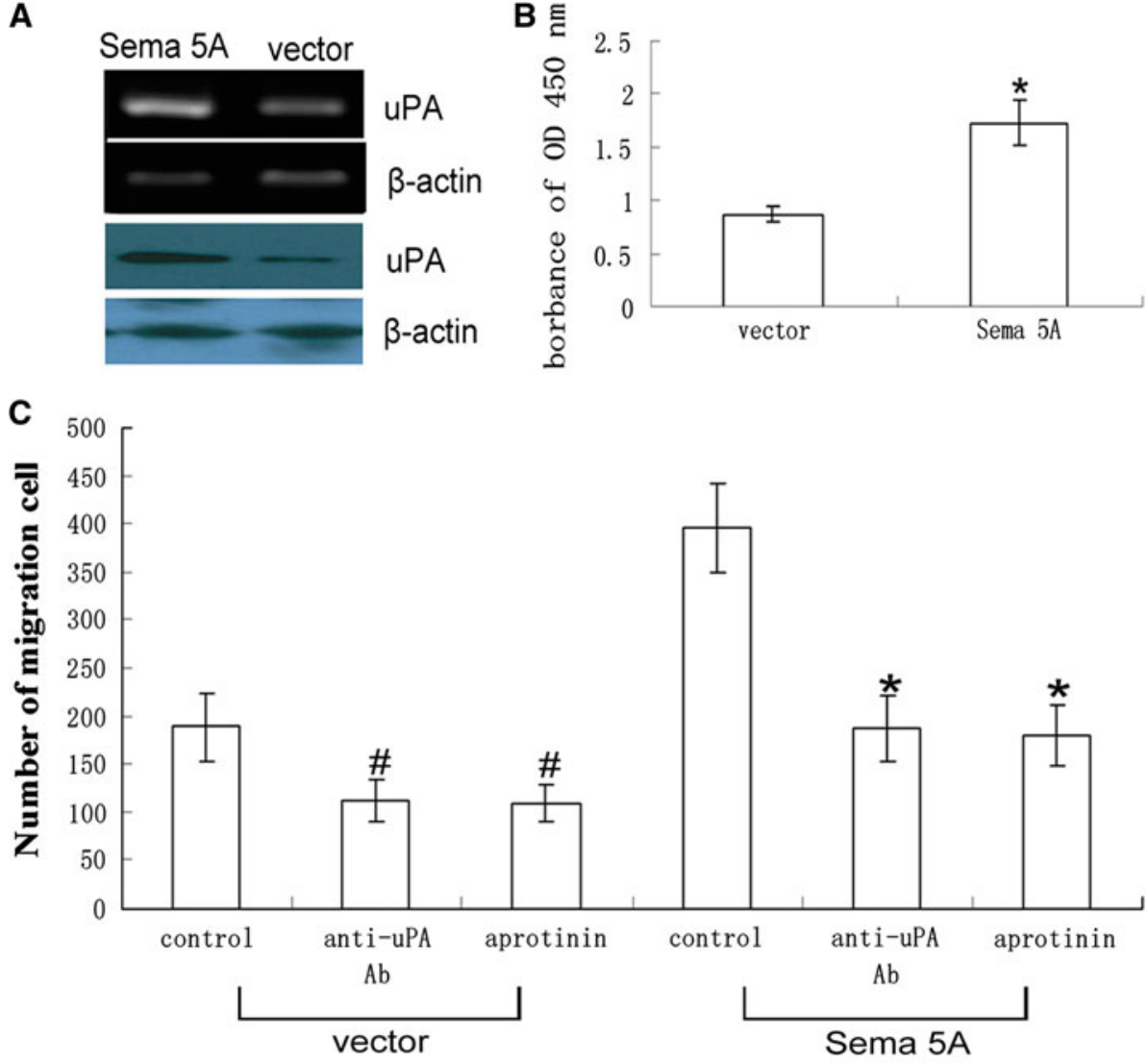

D

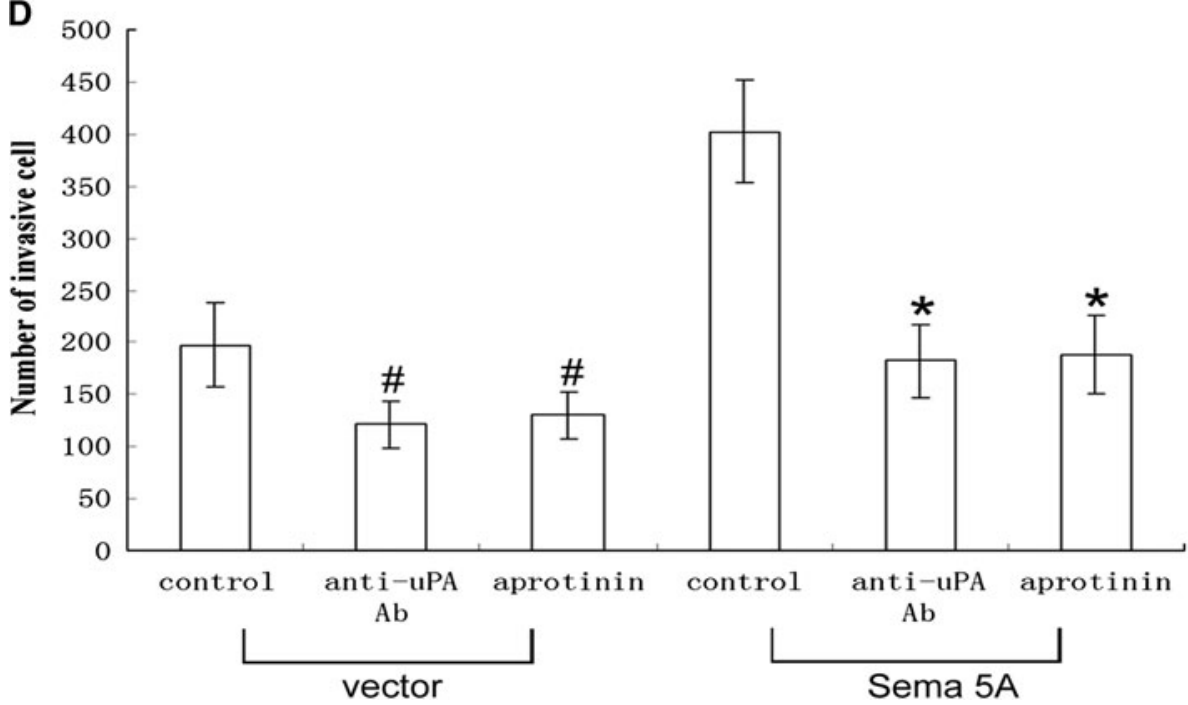

Those results taken together, it could be possible that activation of PI3K/Akt was essential for semaphorin 5Ainduced gastric cancer cell migration and invasion.

\section{PI3K/Akt Act Upstream of uPA}

Western blotting and ELISA assays were used to analyze the expression of uPA in the cells treated with LY294002, Akt-I, which further characterized the signal transduction

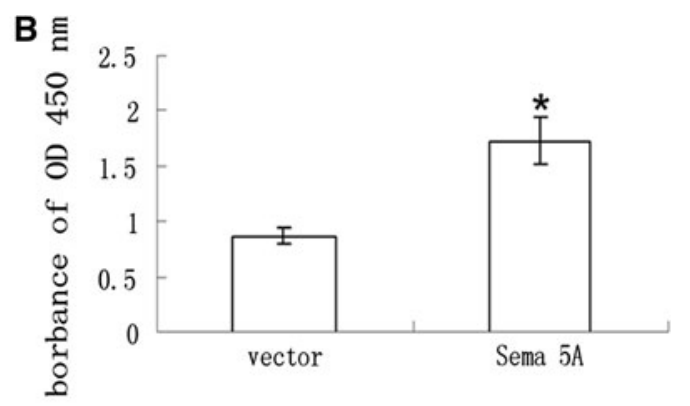

mechanisms involved in gastric cancer cell migration and invasion induced by semaphorin $5 \mathrm{~A}$.

Figure 4d, e showed that preincubation of the cells with the PI3K inhibitor LY294002 clearly reduced the effect of semaphorin 5A on uPA activation. The same result was obtained with Akt-I treatment (Fig. 4e, f). These findings suggest that PI3K/Akt has a specific role in semaphorin 5A-induced expression of uPA. To further confirm this possibility, PTEN, a tumor suppressor protein blocking PI3K-induced signaling, was cotransfected with semaphorin 5A. Like LY294002, this 
Fig. 4 Semaphorin 5A promotes the migration and invasion of AGS cells through the PI3K/Akt/uPA pathway. a, b The treatment of LY, Akt-I induced migration and invasion of AGS cells. c Semaphorin 5A enhances the phosphorylation of Akt, as demonstrated by Western blotting. d-f The treatment of LY, Akt-I reduces semaphorin 5A-induced uPA expression, as demonstrated by Western blotting and Elisa assays, respectively. ${ }^{*} P<0.01$ versus control; ${ }^{\#} P<0.05$ versus control abolishes semaphorin 5A-

A

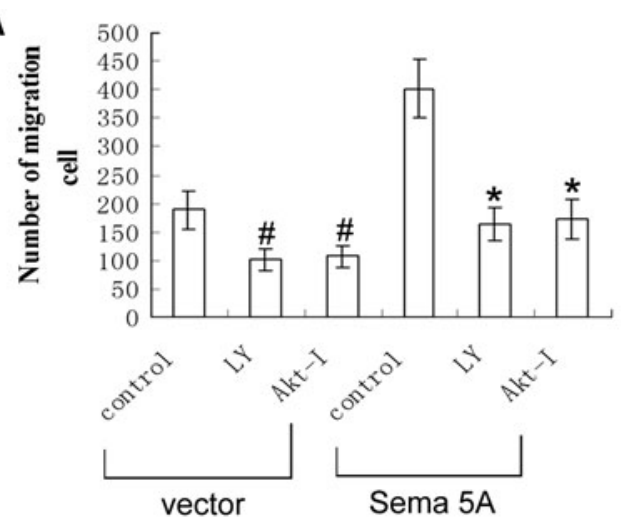

C

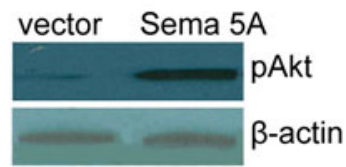

\section{E}

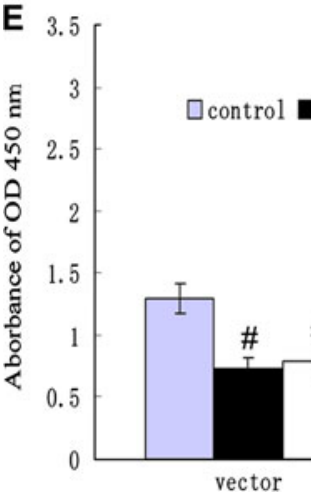

treatment suppressed semaphorin 5A, increasing uPA activity and cell invasion (data not shown). Furthermore, the effects of PTEN were mimicked by the dominant-negative mutant of Akt (Akt-M) (data not shown), suggesting that PI3K and Akt are involved in semaphorin 5A-induced uPA expression.

\section{Discussion}

The invasion of cancer cells is one of the fundamental steps in the metastatic process. Highly invasive cancer cells are capable of passing through matrix membranes, yet the molecular events involved in these mechanisms have not been well identified. Therefore, understanding the molecular mechanism(s) regulating gastric cancer metastasis is a major objective of cancer research. In the present study, we presented the first evidence that semaphorin 5A could promote invasion and metastasis of gastric cancer by regulating uPA expression, at least partially, via the PI3K/Akt signal transduction pathway. These findings significantly advance our understandings of the semaphorin 5A-induced
B

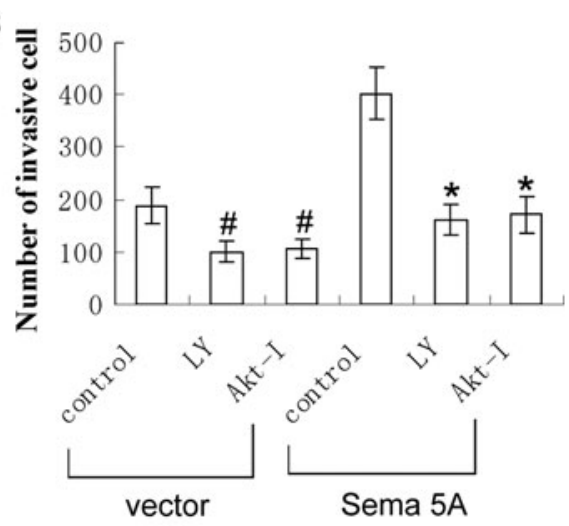

D

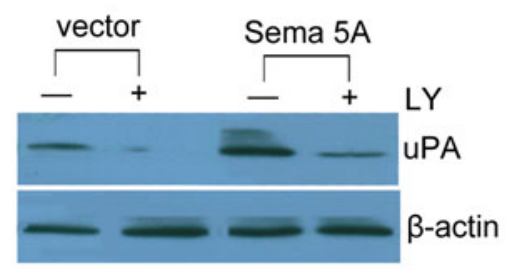

$\mathbf{F}$

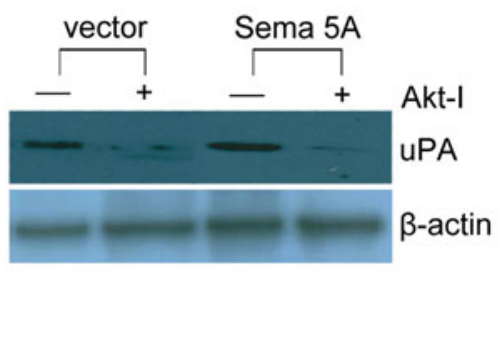

signaling processes that result in the migration and invasion of gastric cancer cells.

Semaphorin $5 \mathrm{~A}$ is a member of the semaphorin family but has received scant attention as compared with other semaphorin family members. Consequently, only limited information is available about its physiologic role and modes of action in human tumors. Although our previous work revealed that semaphorin $5 \mathrm{~A}$ might contribute to the development and progression of gastric carcinoma [4], the exact mechanism(s) by which semaphorin $5 \mathrm{~A}$ enhances the invasion and metastasis of gastric cancer remain(s) unclear.

In order to penetrate into neighboring tissues and metastasize to distant organs, cancer cells require the motility and degradation of the ECM. Under this condition, certain types of ECM-degrading enzymes play a critical role in promoting the migration and subsequent metastasis of cancer cells [13-15]. A well-characterized example of such enzymes is the uPA, a serine proteinase which is overexpressed in many human cancers in a manner associated with their malignancy $[16,17]$. Therefore, we hypothesized that the stimulatory effect of 
semaphorin 5A on tumor invasion and migration is associated with the expression of uPA. The present work demonstrated that, after being transfected with the semaphorin $5 \mathrm{~A}$ gene, expression of uPA in AGS cells at mRNA and protein levels was up-regulated. Furthermore, we also found that the semaphorin 5A-induced cell invasion and migration were strongly blocked by the uPA inhibitor and $\mathrm{Ab}$ against $\mathrm{uPA}$. These data suggest that semaphorin $5 \mathrm{~A}$ may promote the migration and invasion of gastric cancer cells by uPA expression.

The PI3K/Akt pathway has been demonstrated to be an important mediator of tumor cell invasion and migration $[11,12]$. Therefore, we wonder whether the PI3K/Akt pathway is responsible for the migration and invasion of gastric cancer cells and expression of uPA induced by semaphorin $5 \mathrm{~A}$. In the present study, we found that semaphorin 5A overexpression elevated Akt phosphorylation, and that the addition of LY294002 and Akt-I reduced the ability of semaphorin 5A to induce uPA, and abolished semaphorin 5A-induced the migration and invasion of gastric cancer cells. Furthermore, we also found that semaphorin 5A failed to promote uPA expression and cell migration and invasion when PTEN was cotransfected with semaphorin 5A in AGS cells, and that the effects of PTEN were mimicked by the dominant-negative mutant of Akt. Taken together, the results demonstrate that a PI3K/Akt/ uPA pathway is involved in semaphorin 5A-induced migration and invasion of gastric cancer cells.

To our knowledge, this is the first time it has been revealed that semaphorin $5 \mathrm{~A}$ enhances the invasion and metastasis of gastric cancer through the PI3K/Akt/uPA pathway, which not only displays a novel function of semaphorin 5A outside the nervous system but adds more weight to our knowledge of semaphorin 5A. Most importantly, since gastric cancer is one of the most risky cancers, this study may provide some useful information for the development of biomarkers in the clinical diagnosis and also for the design for an appropriate therapeutical strategy of gastric cancer.

\section{Conflict of interest None.}

Open Access This article is distributed under the terms of the Creative Commons Attribution Noncommercial License which permits any noncommercial use, distribution, and reproduction in any medium, provided the original author(s) and the source are credited. The exclusive right to any commercial use of the article is with Springer.

\section{References}

1. Foukakis T, Lundell L, Gubanski M, et al. Advances in the treatment of patients with gastric adenocarcinoma. Acta Oncol. 2007;46:277-285.

2. Harder J, Opitz OG. Gastric cancer-risk factors and medical therapy. Schweiz Rundsch Med Prax. 2006;95:1021-1028.

3. Hundahl SA, Phillips JL, Menck HR. The National Cancer Data Base Report on poor survival of US gastric carcinoma patients treated with gastrectomy: Fifth Edition American Joint Committee on Cancer staging, proximal disease, and the "different disease" hypothesis. Cancer. 2000;88:921-932.

4. Yazdani U, Terman JR. The semaphorins. Genome Biol. 2006;7: 211-224.

5. Kolodkin AL, Matthes DJ, Goodman CS. The semaphorin genes encode a family of transmembrane and secreted growth cone guidance molecules. Cell. 1993;75:1389-1399.

6. Kruger RP, Aurandt J, Guan KL. Semaphorins command cells to move. Nat Rev Mol Cell Biol. 2005;10:789-800.

7. Pan GQ, Ren HZ, Wen JF, et al. Expression of semaphorin $5 \mathrm{~A}$ and its receptor plexin B3 contributes to invasion and metastasis of gastric carcinoma. World J Gastroenterol. 2009;15:2800-2804.

8. Pan G, Lv H, Ren H, Wen J, et al. Elevated expression of semaphorin 5A in human gastric cancer and its implication in carcinogenesis. Life Sci. 2010;86:139-144.

9. Pan G, Zhang X, Ren J, Zhang S, Li J, et al. Semaphorin 5A, an axon guidance molecule, enhances the invasion and metastasis of human gastric cancer through activation of MMP9. Pathol Oncol Res. 2013;19:11-18.

10. Mehlen P, Puisieux A. Metastasis: a question of life or death. Nat Rev Cancer. 2006;6:449-458.

11. Veit C, Genze F, Menke A, et al. Activation of phosphoinositide 3-kinase and extracellular signal regulated kinase is required for glial cell line derived neutrophic factor-induced migration and invasion of pancreatic carcinoma cells. Cancer Res. 2004;64:5291-5300.

12. Qian Y, Zhong X, Flynn DC, et al. ILK mediates filament rearrangements and cell migration and invasion through PI3K/Akt/ Rac1 signaling. Oncogene. 2005;24:3154-3165.

13. Legrand C, Polette M, Tournier JM, de Bentzmann S, et al. uPA/ plasmin system-mediated MMP-9 activation is implicated in bronchial epithelial cell migration. Exp Cell Res. 2001;264:326-336.

14. Kunigal S, Gondi CS, Gujrati M, et al. SPARC-induced migration of glioblastoma cell lines via uPA/uPAR signaling and activation of small GTPase RhoA. Int J Oncol. 2006;29:1349-1357.

15. Look MP, van Putten WL, Duffy MJ, et al. Pooled analysis of prognostic impact of urokinase-type plasminogen activator and its inhibitor PAI-1 in 8377 breast cancer patients. J Natl Cancer Inst. 2002;94:116-128.

16. Hou Y, Okamoto C, Okada K, et al. c-Myc is essential for urokinase plasminogen activator expression on hypoxia-induced vascular smooth muscle cells. Cardiovasc Res. 2007;75:186-194.

17. Xing RH, Rabbani SA. Regulation of urokinase production by androgens in human prostate cancer cells: effect on tumor growth and metastases in vivo. Endocrinology. 1999;140:4056-4064. 